\title{
Is dying in hospital better than home in incurable cancer and what factors influence this? A population-based study
}

\author{
Barbara Gomes $^{1 *}$, Natalia Calanzani ${ }^{1,2}$, Jonathan Koffman ${ }^{1}$ and Irene J. Higginson ${ }^{1}$
}

\begin{abstract}
Background: Studies show that most patients with advanced cancer prefer to die at home. However, not all have equal chances and the evidence is unclear on whether dying at home is better. This study aims to determine the association between place of death, health services used, and pain, feeling at peace, and grief intensity.

Methods: Mortality follow-back study of 352 cancer patients who died in hospital $(n=177)$ or at home $(n=175)$ in London, UK. Bereaved relatives identified from death registrations completed a questionnaire including validated measures of patient's pain and peace in the last week of life and their own grief intensity. We determined factors influencing death at home, and associations between place of death and pain, peace, and grief.

Results: Where people died was, for most $(80 \%)$, the place where they lived during their last week of life. Four factors explained $>91 \%$ of home deaths: patient's preference, relative's preference, home palliative care, or district/community nursing. The propensity of death at home also increased when the relative was aware of incurability and the patient discussed his/her preferences with family. Dying in hospital was associated with more hospital days, fewer general practitioner (GP) home visits, and fewer days taken off work by relatives. Adjusting for confounders, patients who died at home experienced similar pain levels but more peace in their last week of life (ordered log odds ratio $0.69, P=0.007$ ). Grief was less intense for their relatives than for those of patients who died in hospital $(\beta,-0.15$ around time of death and -0.14 at questionnaire completion, $P=0.02$ ).
\end{abstract}

Conclusion: The study suggests that dying at home is better than hospital for peace and grief, but requires a discussion of preferences, GP home visits, and relatives to be given time off work.

Trial registration: National Institute of Health Research (NIHR) Clinical Research Network Portfolio. UKCRN7041.

Keywords: Bereavement, Health care surveys, Home care services, Neoplasms, Pain, Palliative care

\section{Background}

Studies of patients with advanced cancer and the general public show that most people would prefer to die at home $[1,2]$. In the UK, the US, and Canada, more appear to be realising this wish [3-5]. In Japan, Germany, Greece, and Portugal a trend towards institutionalised dying persists [6-9]. Despite differing trends, the most frequent location of death for those dying from cancer is hospital, with marked variations in the odds of home death depending on illness-related, individual, and

\footnotetext{
* Correspondence: barbara.gomes@kcl.ac.uk

${ }^{1}$ King's College London, Cicely Saunders Institute, Department of Palliative Care, Policy and Rehabilitation, Bessemer Road, SE5 9PJ London, UK Full list of author information is available at the end of the article
}

environmental factors [10-12]. Furthermore, the most important aim towards the end of life is to ensure the best possible palliative outcomes. Population ageing and larger numbers of people dying from cancer represent a demographic imperative for healthcare systems to ensure a dignified death for all $[13,14]$.

There is some evidence showing better results on psychological, social, and holistic measures of well-being in the last weeks or days of life for patients dying at home compared to hospital [15]. However, findings on symptoms and family outcomes are inconsistent, particularly for two widely researched outcomes: pain and grief [16-19]. Tang [20] found that pain was more likely for patients who died at home (compared to hospital), 
while Escobar Pinzon et al. [21] found the opposite (even when accounting for confounders) and Jordhoy et al. [22] found no difference. Addington-Hall and Karlsen, in the Regional Study of Care for the Dying (RSCD) in the UK [18], reported higher levels of grief among relatives of patients who died at home (compared to elsewhere), while Wright et al. [19], in the Coping with Cancer study in the US, found that relatives of patients who died in hospital were more likely to develop prolonged grief disorder. Ringdal et al. [23], however, in a randomised controlled trial of home palliative care, observed no difference by place of death. In an earlier study in London, Parkes [16] had reported worse symptom control for patients who died at home as opposed to hospital.

In order to meet patient preference at no expense of the best possible outcomes, it is crucial to find out whether death at home is better for patients and families. This study aimed to determine the association between place of death, health services used, and pain, feeling at peace, and grief intensity. We first identified factors influencing the propensity of dying at home rather than in hospital, and then compared the three outcomes (pain, peace, and grief).

\section{Methods}

\section{Design, setting, and sample}

QUALYCARE is a case-control study that used a mortality follow-back postal survey methodology of bereaved relatives (UKCRN7041; protocol in [24]). This is a wellestablished method internationally and recommended by the UK National End of Life Care Strategy in 2008 [25]. It was deemed appropriate for this study given the large sample size required and the need to examine common time periods before death for all in the sample.

The study took place in four health districts in London covering 1.3 million residents. An ecological analysis of cancer home death rates and socioeconomic deprivation levels informed the choice of districts to capture variation (Additional file 1).

Participants were identified from death registrations and approached by the Office for National Statistics (ONS). These were persons that registered the death of people aged $\geq 18$ years who died from cancer (ICD-10 codes C00-D48) during a 1-year period (March 5, 2009, to March 4, 2010) having lived in the study districts. Patients were excluded if a coroner registered the death, since coroners would not be able to provide sufficient information about the patient's care and outcomes.

The eligible sample included all who died at home and a random sample of 150 who died in a National Health System non-psychiatric hospital in each district (or all when the eligible number was $<150$, which happened in the two smaller districts). Cases comprised persons who died at home and controls were persons who died in hospital. A sample of 350 patients was chosen to detect a minimum standardised difference of 0.30 (power $80 \%$, significance 0.05 ) and allow regression analyses with a maximum of 35 variables entered and 19 retained, following Altman's recommendations ( $\mathrm{n} / 10$ variables and square root of sample size, respectively) [26].

Potential participants were contacted in writing by the ONS on behalf of the research team 4-10 months after registering the patient's death, and asked to complete a structured postal questionnaire. Up to two reminders were sent to people who did not respond at 2 and 4 weeks after the initial posting; the second reminder included another copy of the questionnaire. In addition, pseudo-anonymised death registration data were provided by the ONS.

\section{Case ascertainment}

Information on place of death is systematically recorded in death registration files, as reported by the informant (i.e. person who registers the death) within 5 days after the death occurred. We validated this information against questionnaire data. There were only two disagreements (Additional file 2). We also asked the respondents how long the patient had been in the place where they died.

\section{Measurement of factors and outcomes associated with home death}

Our approach to measuring factors and outcomes associated with home death was guided by systematic reviews, a theoretical model of home death in cancer [11], and findings from the pilot preceding the study [27]. Additional files 3 and 4 include details of the factors and outcomes analysed; the information was collected in the same manner for cases and controls. We used validated specific health outcome measures: Palliative care Outcome Scale (POS) items to measure pain interference or affect on the patient (item ranging $0-4$, higher scores meaning more pain interference) and the overall grade of peace during the last week of life (ranging 0-5, higher scores meaning more frequent feeling at peace) $[28,29]$; and the Texas Revised Inventory of Grief (TRIG) to measure the respondent's own grief intensity around time of death (TRIG I; reported retrospectively; scale ranging 8-40, higher scores meaning greater grief intensity) and at questionnaire completion (TRIG II; scale ranging from 13-65) [30]. Cronbach's alpha estimates were 0.86 (TRIG I) and 0.93 (TRIG II) in the study. According to Bland and Altman [31], this demonstrates good internal consistency for comparing groups ( $\alpha$ values of 0.70 to 0.80 are regarded as satisfactory for this purpose).

\section{Approvals and ethics}

A National Health System research ethics committee (REC), the London - Dulwich REC, formerly King's 
College London REC, approved the study (ref: 09/ H0808/85). Together with the invitation letter and questionnaire, potential participants were mailed the study information sheet, a reply slip to decline participation, and a bereavement information leaflet. Return of a completed questionnaire was taken as informed consent. We followed piloted procedures for dealing with queries and distress [32] and checked returned questionnaires for participants requiring follow-up action (particularly answers to grief-related questions). If concerns arose and participants had agreed to be contacted, they were informed about local sources of support [24]. A data access agreement with the ONS governed the handling of death registration data.

\section{Analysis}

Factors

We developed a multivariate model of factors associated with home death in two stages. Firstly, direct logistic regression tested a baseline model with nine variables covering all groups of factors proposed in the theoretical model: illness related, individual, and environmental (Additional file 5) [24]. Secondly, one-by-one, we added detail on cancer type and other variables associated with home death with $P<0.250$ in bivariate analysis, retaining those that stayed significant $(P<0.050)$. Independent variables with near-zero cells and multicollinearity that cause quasi-separation of the dependent variable lead to mathematical problems in logistic regression rendering instability to models [33], and were therefore excluded. Variables with $>10 \%$ missing data were also excluded.

A sub-group analysis tested the final model only for patients who preferred to die at home. This aimed to help clinicians make decisions when caring for patients they know wish to die at home.

Finally, a sensitivity analysis examined the impact of non-response on the association of home death with five variables (available through death registrations for participants and non-participants): patient's gender and age, country of birth, cancer type, and deprivation (measured using the Index of Multiple Deprivation 2010, in quintiles referring to the area of last residence of the deceased; more details in the footnote of Table 1 [34].

\section{Outcomes}

Multivariate ordinal regression (for pain and peace; nonnormally distributed) and linear regression (for grief) determined associations with place of death. Potential confounders were entered and retained if significant $(P<0.050)$, alongside factors associated with home death in our final model.

The models included the variable district to control for any design effect due to stratified sampling. When $>10 \%$ of individuals were excluded from the model due to missing data, $x^{2}$ tests identified any differential by place of death. Analyses were conducted in SPSS for Windows (version 19.0).

\section{Results}

\section{Response rates and sample characteristics}

We sampled 881 patients; 366 constituted cases and 515 were controls in the case-control study (flowchart in Additional file 6). Related to this sample, 352 bereaved relatives $(40.0 \%)$ completed the questionnaire. They were contacted a median of 232 days after the patient died, i.e. 7 months (interquartile range (IQR), 189280 days), with no significant difference between cases and controls.

Patients died at a median age of 76 years (IQR, 67-83) and $55 \%$ were men (Table 1). The two most common cancer groups were digestive $(35 \%$ of men, $23 \%$ of women) and respiratory or intra-thoracic ( $21 \%$ of men, $25 \%$ of women). Most of the proxy respondents (66\%) were women and $90 \%$ were first line relatives of the patient (i.e. spouses, partners, offspring, siblings, or parents). Their median age was 59 years (IQR, 49-70). Home death was preferred by $>66 \%$ of patients in both groups and $92 \%$ of relatives of patients who died at home, but only by $32 \%$ of relatives of patients who died in hospital, with $<17 \%$ of relatives in both groups changing their mind in the patient's last 3 months of life.

For most decedents $(80 \%)$, where they died was also where they lived during their last week of life (Fig. 1). Of those who died in hospital, $28 \%$ were admitted in the last week of life, $51 \%$ in the last month but prior to the last week, and $21 \%>1$ month before they died. Of those who died at home, $45 \%$ had not been admitted for the whole of their last 6 months of life and $11 \%$ had gone home in their last week.

\section{Factors associated with dying at home rather than in hospital}

Figure 2 summarises the associations contrasting bivariate and multivariate results. The first model includes unadjusted associations found through bivariate analysis (Additional file 7) and the second model includes adjusted but also the strongest unadjusted associations that due to near-zero cell frequencies and multicollinearity could not be included in multivariate logistic regression. Four inter-related factors explained $>91 \%$ of home deaths and $>67 \%$ of hospital deaths: preference for home death by the patient, preference for home death by the patient's relative, receipt of home palliative care in the last 3 months of life, receipt of district/community nursing in the last 3 months of life. In addition, patients who died in hospital were less likely to have had Marie Curie nursing (these nurses care for people at home in the last few months or weeks of their lives, with the core 
Table 1 Sample characteristics

\begin{tabular}{|c|c|c|c|}
\hline & $\begin{array}{l}\text { All } \\
(n=352)\end{array}$ & $\begin{array}{l}\text { Home death } \\
(\mathrm{n}=175)\end{array}$ & $\begin{array}{l}\text { Hospital death } \\
(n=177)\end{array}$ \\
\hline \multicolumn{4}{|l|}{ Patient's gender } \\
\hline Male & $192(54.5 \%)$ & $94(53.7 \%)$ & $98(55.4 \%)$ \\
\hline Female & $160(45.5 \%)$ & $81(46.3 \%)$ & $79(44.6 \%)$ \\
\hline \multicolumn{4}{|l|}{ Patient's age } \\
\hline Median in years (IQR) & $76(67-83)$ & $76(66-83)$ & $76(67-83.5)$ \\
\hline \multicolumn{4}{|l|}{ Type of cancer (underlying cause of death) } \\
\hline Digestive & $105(29.8 \%)$ & $59(33.7 \%)$ & $46(26.0 \%)$ \\
\hline Respiratory and intra-thoracic organs & $80(22.7 \%)$ & $40(22.9 \%)$ & $40(22.6 \%)$ \\
\hline Eye, brain, and other parts of the central nervous system & $13(3.7 \%)$ & $11(6.3 \%)$ & $2(1.1 \%)$ \\
\hline Breast & $18(5.1 \%)$ & $9(5.1 \%)$ & $9(5.1 \%)$ \\
\hline Lymphoid, haematopoietic, and related tissue & $26(7.4 \%)$ & $8(4.6 \%)$ & $18(10.2 \%)$ \\
\hline Genitourinary & $67(19.0 \%)$ & $25(14.3 \%)$ & $42(23.7 \%)$ \\
\hline Unspecified and other & $43(12.2 \%)$ & $23(13.1 \%)$ & $20(11.3 \%)$ \\
\hline \multicolumn{4}{|l|}{ Mobility at 3 months to death (EQ-5D) } \\
\hline No problems & $95(28.4 \%)$ & $42(25.6 \%)$ & $53(31.0 \%)$ \\
\hline Some problems & $211(63.0 \%)$ & $106(64.6 \%)$ & $105(61.4 \%)$ \\
\hline Confined to bed & $29(8.7 \%)$ & $16(9.8 \%)$ & $13(7.6 \%)$ \\
\hline \multicolumn{4}{|l|}{ Self-care at 3 months to death (EQ-5D) } \\
\hline No problems & $148(44.7 \%)$ & $68(42.2 \%)$ & 80 (47.1\%) \\
\hline Some problems & $128(38.7 \%)$ & $68(42.2 \%)$ & $60(35.3 \%)$ \\
\hline Unable to wash/dress her/himself & $55(16.6 \%)$ & $25(15.5 \%)$ & $30(17.6 \%)$ \\
\hline \multicolumn{4}{|l|}{ Usual activities at 3 months to death (EQ-5D) } \\
\hline No problems & $76(22.8 \%)$ & $31(18.8 \%)$ & $45(26.6 \%)$ \\
\hline Some problems & $152(45.5 \%)$ & $82(49.7 \%)$ & $70(41.4 \%)$ \\
\hline Unable to perform usual activities & $106(31.7 \%)$ & $52(31.5 \%)$ & $54(32.0 \%)$ \\
\hline \multicolumn{4}{|l|}{ Patient's country of birth } \\
\hline UK/reland & $288(81.8 \%)$ & $142(81.1 \%)$ & $146(82.5 \%)$ \\
\hline Elsewhere & $64(18.2 \%)$ & $33(18.9 \%)$ & $31(17.5 \%)$ \\
\hline \multicolumn{4}{|l|}{ Patient's ethnicity } \\
\hline White British/lrish & 291 (84.6 \%) & $145(84.8 \%)$ & $146(84.4 \%)$ \\
\hline White other/unspecified & $21(6.1 \%)$ & $13(7.6 \%)$ & $8(4.6 \%)$ \\
\hline Other & $32(9.3 \%)$ & $13(7.6 \%)$ & $19(11.0 \%)$ \\
\hline \multicolumn{4}{|l|}{ IMD 2010 (patient's residence area) $^{a}$} \\
\hline $5^{\text {th }}$ quintile (least deprived) & $89(25.3 \%)$ & $46(26.3 \%)$ & $43(24.3 \%)$ \\
\hline $4^{\text {th }}$ quintile & 69 (19.6\%) & 41 (23.4 \%) & $28(15.8 \%)$ \\
\hline $3^{\text {rd }}$ quintile & $55(15.6 \%)$ & $31(17.7 \%)$ & $24(13.6 \%)$ \\
\hline $2^{\text {nd }}$ quintile & $85(24.1 \%)$ & $35(20.0 \%)$ & $50(28.2 \%)$ \\
\hline $1^{\text {st }}$ quintile (most deprived) & $54(15.3 \%)$ & $22(12.6 \%)$ & $32(18.1 \%)$ \\
\hline \multicolumn{4}{|l|}{ Patient's marital status } \\
\hline Married/with partner & $199(58.0 \%)$ & $117(68.8 \%)$ & $82(47.4 \%)$ \\
\hline Widowed & $86(25.1 \%)$ & 34 (20.0 \%) & $52(30.1 \%)$ \\
\hline Divorced/separated & $25(7.3 \%)$ & $9(5.3 \%)$ & $16(9.2 \%)$ \\
\hline Never married & $33(9.6 \%)$ & $10(5.9 \%)$ & $23(13.3 \%)$ \\
\hline
\end{tabular}


Table 1 Sample characteristics (Continued)

\begin{tabular}{|c|c|c|c|}
\hline \multicolumn{4}{|l|}{ Patient's living with relatives } \\
\hline Yes & $249(71.6 \%)$ & $145(83.8 \%)$ & $104(59.4 \%)$ \\
\hline No & 99 (28.4 \%) & 28 (16.2\%) & $71(40.6 \%)$ \\
\hline \multicolumn{4}{|l|}{ Patient's preference for PoD } \\
\hline Home & $262(83.7 \%)$ & $168(97.7 \%)$ & $94(66.7 \%)$ \\
\hline Other or no preference & $51(16.3 \%)$ & $4(2.3 \%)$ & $47(33.3 \%)$ \\
\hline \multicolumn{4}{|l|}{ Relative's gender } \\
\hline Male & $118(33.8 \%)$ & $53(30.6 \%)$ & $65(36.9 \%)$ \\
\hline Female & $231(66.2 \%)$ & $120(69.4 \%)$ & $111(63.1 \%)$ \\
\hline \multicolumn{4}{|l|}{ Relative's age } \\
\hline Median in years (IQR) & $59(49-70)$ & $60(50-71)$ & $57(49-68)$ \\
\hline \multicolumn{4}{|c|}{ Relative's relationship to patient } \\
\hline Spouse/partner & $147(41.9 \%)$ & $85(48.6 \%)$ & $62(35.2 \%)$ \\
\hline Son/daughter & $142(40.5 \%)$ & 75 (42.9 \%) & $67(38.1 \%)$ \\
\hline Brother/sister & $20(5.7 \%)$ & $4(2.3 \%)$ & $16(9.1 \%)$ \\
\hline Other & $42(12.0 \%)$ & $11(6.3 \%)$ & $31(17.6 \%)$ \\
\hline \multicolumn{4}{|c|}{ Relative's preference for PoD at 3 months to death } \\
\hline Home & $215(61.8 \%)$ & $159(91.9 \%)$ & $56(32.0 \%)$ \\
\hline Other or no preference & $133(38.2 \%)$ & $14(8.1 \%)$ & $119(68.0 \%)$ \\
\hline \multicolumn{4}{|c|}{ Change in relative's preference for PoD in 3 months prior death } \\
\hline Yes & $42(12.7 \%)$ & $16(9.5 \%)$ & $26(16.0 \%)$ \\
\hline No & $289(87.3 \%)$ & $153(90.5 \%)$ & $136(84.0 \%)$ \\
\hline
\end{tabular}

a Index of Multiple Deprivation (IMD) 2010 national quintile of the area of last residence of the deceased. This information was provided by the Office for National Statistics based on death registration information of the patient's lower layer super output area of residence (LSOA). The IMD 2010 score is a measure based on 38 indicators, chosen to cover a broad range of economic, social, and housing issues, into a single relative deprivation score for each LSOA in England [34]. The different domains are combined using appropriate weights to calculate the IMD 2010 score, an overall measure of multiple deprivation experienced by people living in the respective area. This represents unmet needs caused by lack of resources of all kinds (income, employment, health and disability, education skills and training, barriers to housing and other services, crime and living environment)

Percentages may not add to $100 \%$ due to rounding

IQR, Interquartile range; PoD, Place of death

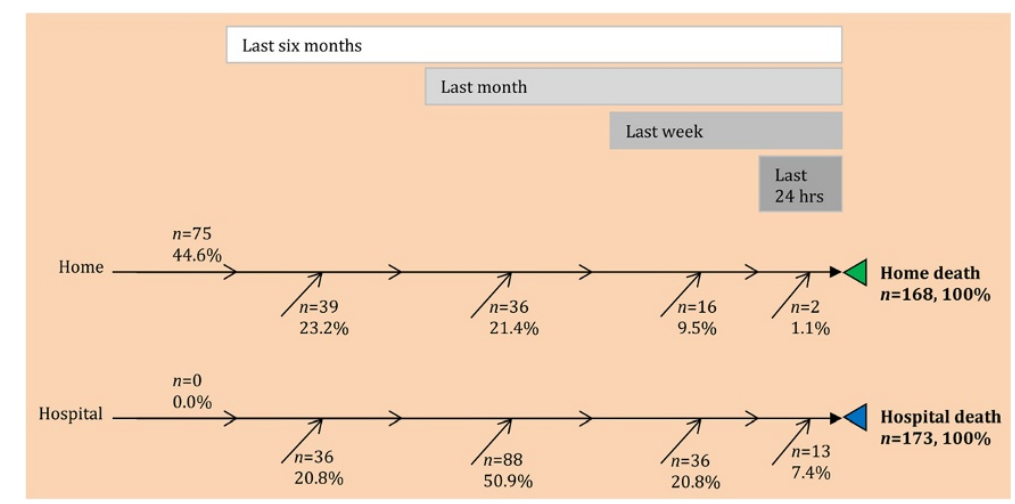

Fig. 1 Permanence in place versus timing of last transition by place of death. The figure shows how long the patients were in the place where they died. Numbers and percentages by place of death are placed backwards from death according to the time period when the last transition happened. For example, 75 out of 168 people who died at home (45\%) were at home for 6 months or more (with no transition). Two (1 \%) went home in their last 24 hours of life. Eleven patients had missing data: seven home deaths, four hospital deaths (including two people who gave inconsistent information). 


\section{Model 1. Unadjusted associations ${ }^{\mathrm{a}}$}

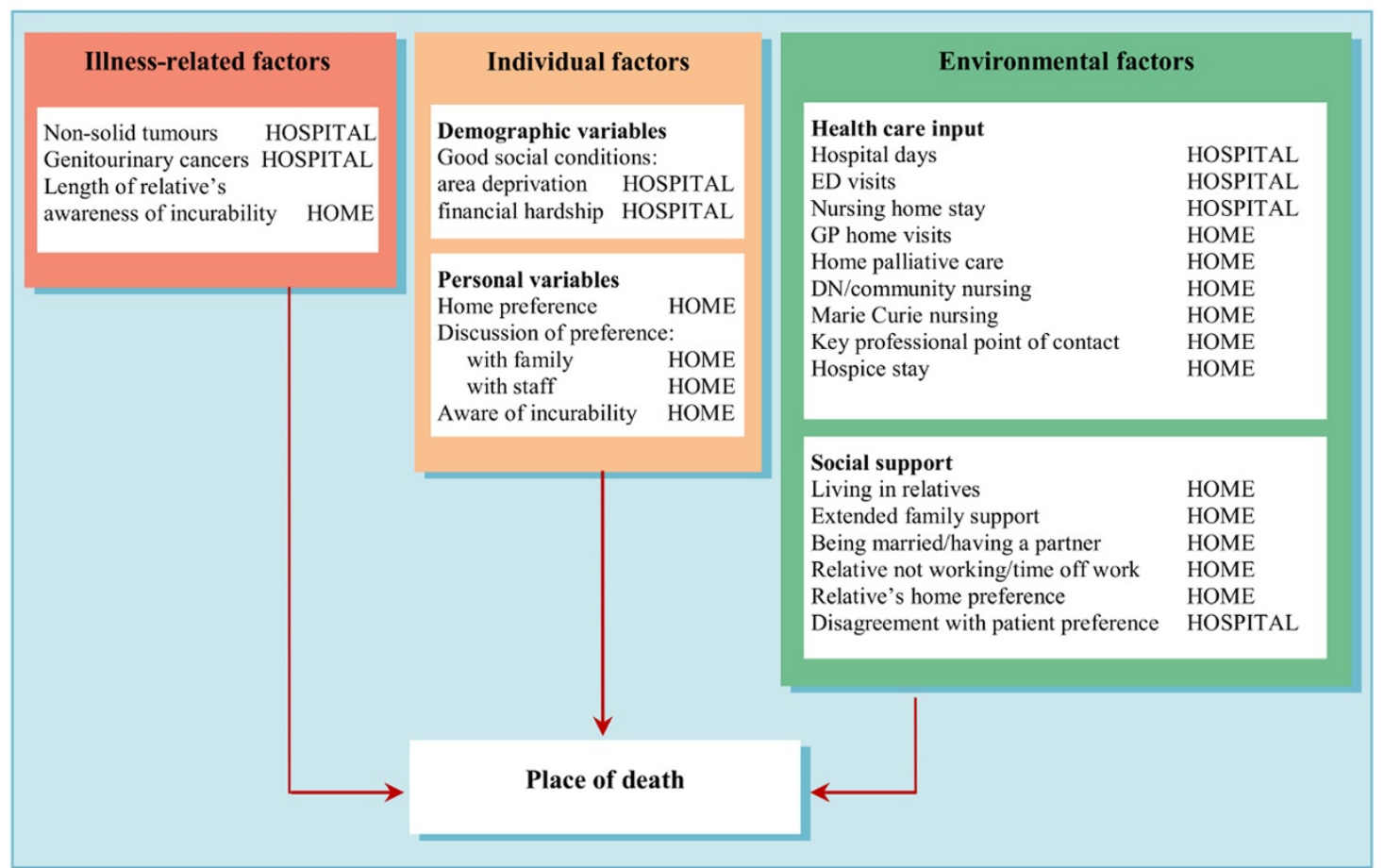

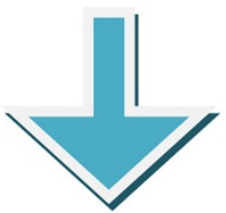

Model 2. Adjusted and strongest unadjusted associations ${ }^{\mathrm{b}}$

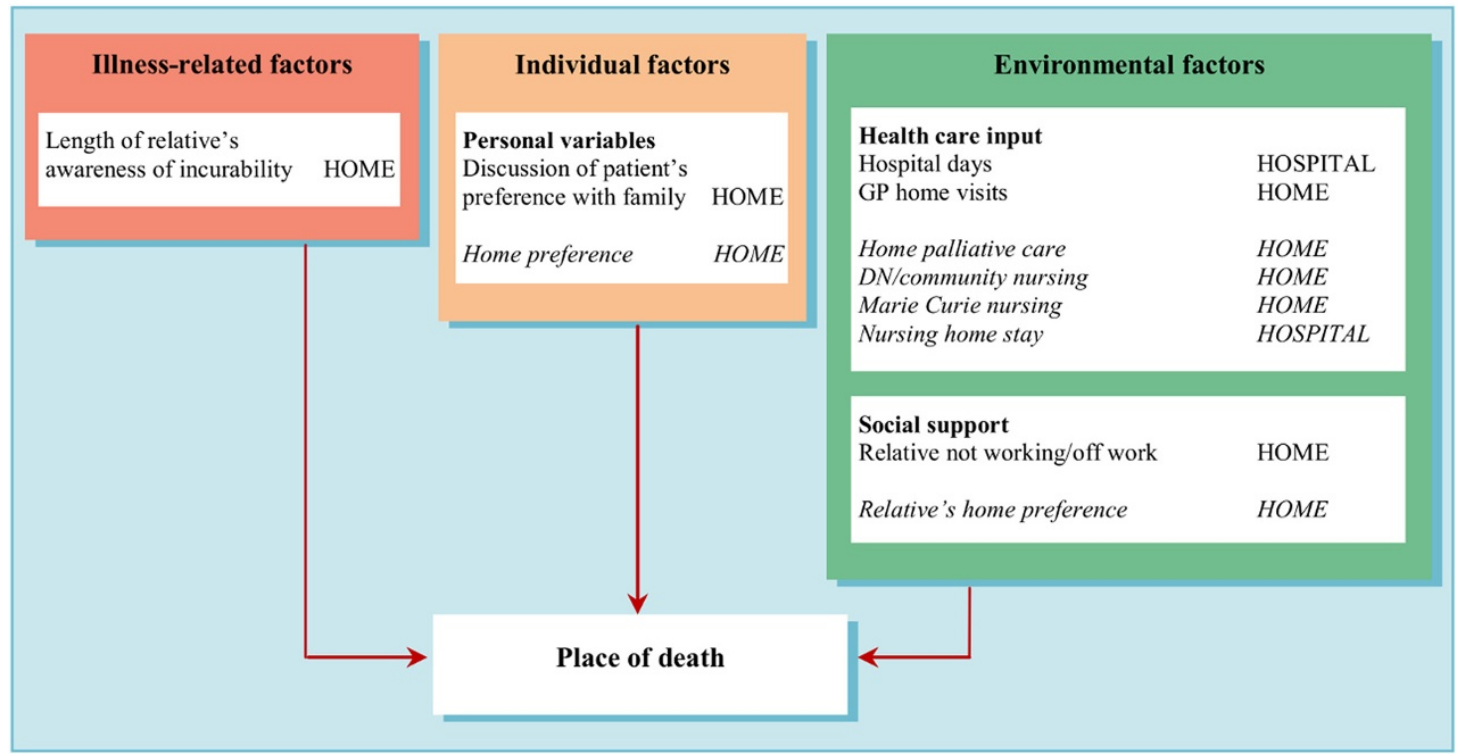

Fig. 2 Unadjusted and adjusted associations with death at home. ${ }^{a}$ Factors identified through bivariate analysis $(P<0.05) ;{ }^{b}$ Factors retained in the final multivariate model $(P<0.05)$ except for those in italic, which show the strongest unadjusted associations but due to near-zero cell frequencies and multicollinearity with place of death could not be included in the logistic regression model 
service being one-to-one overnight nursing; $4 \%$ in the hospital group compared to $41 \%$ in the home group). Only seven patients who received care from Marie Curie nurses died in hospital. Three other variables had $>10 \%$ missing data and were therefore excluded from further analysis (whether the patient discussed their preference for place of death with professionals, whether the patient's preference for place of death differed from the relative's preference, and whether there had been a key professional point of contact in the 3 months before death).

Figure 3 presents the relative influence of five factors in multivariate analysis. Two originated from the baseline model: hospital days and general practitioner (GP) home visits. Three represent new factors: length of relative's awareness of incurability, discussion of patient's preference for place of death with family, and relative's work arrangements in the last 3 months before the patient died. All five associations were statistically significant $(P \leq 0.001)$, although there was a differential in missing data, with more information missing in the hospital group than in the home group (31 \% and $20 \%, P=0.023$ ).

A gradient was evident in the relationships of home death with hospital days and GP home visits (Fig. 3). When patients stayed 15-28 days in hospital during the last 3 months of life, the odds of dying at home were $75 \%$ lower compared to patients with 0-7 days in hospital (adjusted odds ratio (AOR), 0.25; 0.10-0.61). Furthermore, the odds decreased by $91 \%$ for patients who were in hospital for more than 28 days in the last 3 months of life (AOR, 0.09; 0.03-0.25). Patients who received three or more GP home visits during their last
3 months of life had six times greater odds of dying at home compared to patients with just one or no GP home visits (AOR, 6.27; 2.83-13.91). Those with two visits also had greater odds of dying at home (AOR, $3.42 ; 1.23-9.55)$. Home death odds were higher when relatives knew of incurability $>1$ week before death (AOR, 6.51; 2.84-14.91), when patients discussed their preferences with family (AOR, 3.39; 1.63-7.04), and if relatives took $>14$ days off work in the last 3 months before the patient died (AOR, 9.94; 2.56-38.65 versus <4 days off) or were not working (AOR, 3.70; 1.28-10.68).

\section{Sub-group and sensitivity analyses}

Testing the five-factor model on patients who preferred to die at home (i.e. excluding 38 patients who preferred to die elsewhere and 13 who had no preference), all factors remained significant except for whether the patient discussed their preference for place of death with family. Sensitivity analysis examining the impact of non-response on the results showed no differences on the influence that the five factors available for this analysis had on home death (patient's gender, age, cancer type, country of birth, and deprivation; analyses in Additional files 8 and 9).

\section{Differences in pain, peace, and grief by place of death}

The results for pain and peace were maintained in adjusted analyses (Table 2). Based on respondents' accounts, we found that the level of pain experienced by patients in their last week of life was no different for those who died at home than for those who died in hospital (median 1 (slightly, IQR, 0-2) compared to 2 (moderately, 0-2) in POS item ranging $0-4 ; \mathrm{M}-\mathrm{W}$
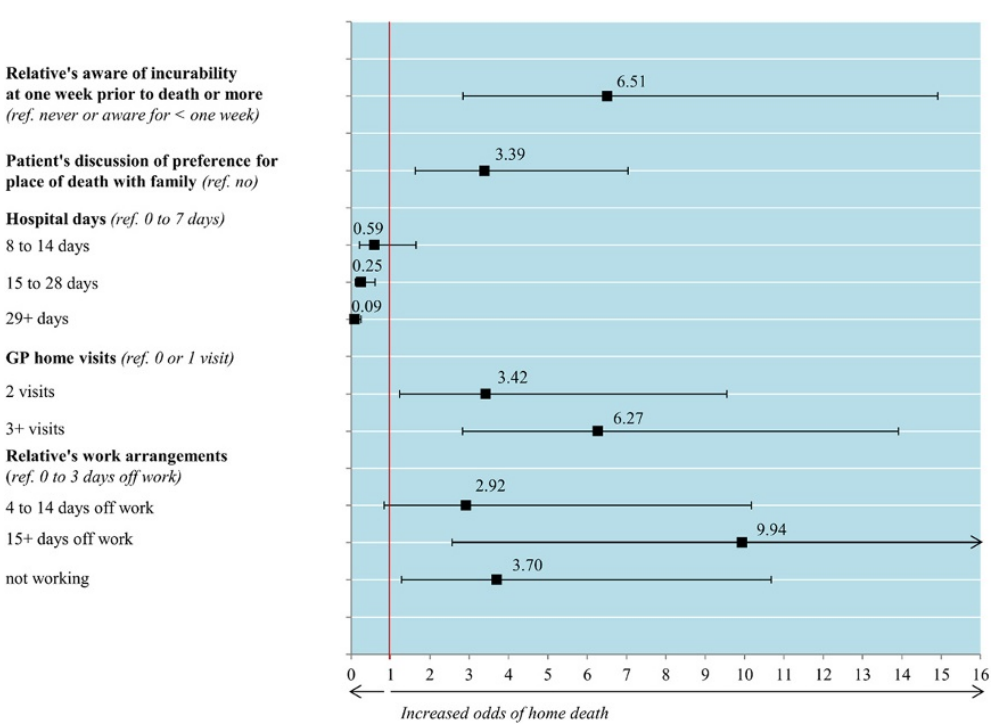

Fig. 3 Five factors independently associated with death at home rather than in hospital. Factors retained in the final multivariate model $(P<0.050)$. The dots present adjusted odds ratios and horizontal lines indicate $95 \%$ confidence intervals. The model was statistically reliable [Hosmer and Lemeshow $X^{2}(8,263)=4.721, P=0.787$ ]; it correctly classified $82 \%$ of the cases (persons who died at home) and $79 \%$ of the controls (persons who died in hospital) 
$(335)=15.456, z=1.671, P=0.095)$. Regardless of severity level, the prevalence of pain was $61.9 \%$ among patients who died at home and $70.1 \%$ among patients who died in hospital. Moderate to overwhelming pain was experienced by $53.3 \%$ of patients in the hospital group as opposed to $44.0 \%$ of those in the home group.

Patients who died at home were reported to feel more frequently at peace during their last week of life than patients who died in hospital (median 4 (most of the time, IQR, 3-5) compared to 3 (some of the time, 1.5-4) in POS item ranging $0-5, \mathrm{M}-\mathrm{W}(330)=9.809, z=-4.546$, $P<0.001)$. A minority $(11.8 \%$ of patients who died at home and $24.8 \%$ of those who died in hospital) were not very often or not at all at peace in their last week of life.
The grief intensity experienced by the respondents around time of death and at questionnaire completion (median of 7 months after the patient died) was similar in the home and hospital groups (mean, 20.52 (SD, 7.91) and 20.78 (8.25), respectively, in TRIG I scale ranging 8-40, $t$-test $(318)=-0.281, P=0.779$; mean, $45.02(11.26)$ and 43.11 (14.10), respectively, in TRIG II scale ranging 13-65, $t$-test $(299)=1.327, P=0.185)$. However, once confounders were taken into account (stronger grief reactions were associated with spouses/partners, presence at time of death, family discussion of preferences for place of death and relative's time off work in the last 3 months before the patient died), the levels of grief were less intense when the patient died at home compared to hospital, both at the time of death $(\beta-0.15, P=0.020)$ and questionnaire completion $(\beta-0.14, P=0.023$; Table 3$)$.

Table 2 Multivariate ordinal regressions of factors associated with pain and peace

\begin{tabular}{|c|c|c|c|c|c|c|c|}
\hline & \multicolumn{4}{|c|}{ Unadjusted } & \multicolumn{3}{|c|}{ Adjusted } \\
\hline & $\mathrm{n}$ & Median score (IQR) & $\begin{array}{l}\text { Ordered log OR } \\
(95 \% \mathrm{Cl})\end{array}$ & $P$ value & $\mathrm{n}$ & $\begin{array}{l}\text { Ordered log OR } \\
(95 \% \mathrm{Cl})\end{array}$ & $P$ value \\
\hline \multicolumn{8}{|l|}{ Pain in last week of life (POS item) } \\
\hline \multicolumn{8}{|l|}{ Place of death } \\
\hline Hospital & 167 & $2(0-2)$ & Ref. & & 166 & Ref. & \\
\hline Home & 168 & $1(0-1)$ & $-0.33(-0.72$ to 0.06$)$ & 0.094 & 168 & $-0.25(-0.65$ to 0.15$)$ & 0.228 \\
\hline \multicolumn{8}{|l|}{ Relative's relationship to the patient } \\
\hline Spouse/partner & 139 & $1(0-2)$ & Ref. & & 139 & Ref. & \\
\hline Son/daughter & 135 & $1(0-2)$ & $0.39(-0.04$ to 0.82$)$ & 0.076 & 135 & $0.38(-0.05$ to 0.80$)$ & 0.087 \\
\hline Brother/sister & 20 & $2(1-2.5)$ & 1.03 (0.19 to 1.88$)$ & 0.017 & 20 & 0.94 (0.08 to 1.80$)$ & 0.031 \\
\hline Other & 40 & $1(0-2)$ & $0.47(-0.17$ to 1.10$)$ & 0.148 & 40 & $0.38(-0.26$ to 1.03$)$ & 0.245 \\
\hline \multicolumn{8}{|l|}{ Peace in last week of life (POS item) } \\
\hline \multicolumn{8}{|l|}{ Place of death } \\
\hline Hospital & 161 & $3(1.5-4)$ & Ref. & & 140 & Ref. & \\
\hline Home & 169 & $4(3-5)$ & 0.93 (0.52 to 1.33$)$ & $<0.001$ & 160 & 0.69 (0.19 to 1.19$)$ & 0.007 \\
\hline \multicolumn{8}{|l|}{ Relative's relationship to the patient } \\
\hline Spouse/partner & 136 & $4(3-4)$ & Ref. & & 124 & Ref. & \\
\hline Son/daughter & 137 & $4(3-4)$ & $-0.14(-0.57$ to 0.29$)$ & 0.510 & 126 & $-0.16(-0.62$ to 0.30$)$ & 0.489 \\
\hline Brother/sister & 15 & $3(2-4)$ & $-0.85(-1.80$ to 0.10$)$ & 0.080 & 12 & $-0.88(-1.95$ to 0.20$)$ & 0.112 \\
\hline Other & 41 & $3(1.5-4)$ & $-0.75(-1.38$ to -0.12$)$ & 0.019 & 38 & $-0.51(-1.17$ to 0.16$)$ & 0.138 \\
\hline \multicolumn{8}{|l|}{ Length of relative's awareness of incurability } \\
\hline Never or aware for less than one week & 76 & $3(1-4)$ & Ref. & & 73 & Ref. & \\
\hline Aware for one week or more & 237 & $4(3-4)$ & 0.65 (0.18 to 1.12$)$ & 0.006 & 227 & 0.69 (0.19 to 1.18$)$ & 0.389 \\
\hline \multicolumn{8}{|c|}{$\begin{array}{l}\text { Patient's preference for place of death discussed } \\
\text { with family }\end{array}$} \\
\hline No & 122 & $4(2-4)$ & Ref. & & 115 & Ref. & \\
\hline Yes & 193 & $4(3-4)$ & 0.79 (0.38 to 1.21$)$ & $<0.001$ & 185 & 0.64 (0.17 to 1.11$)$ & 0.008 \\
\hline
\end{tabular}


Table 3 Multivariate linear regressions of factors associated with grief

\begin{tabular}{|c|c|c|c|c|c|c|c|c|c|}
\hline & \multicolumn{5}{|c|}{ Unadjusted } & \multicolumn{4}{|l|}{ Adjusted } \\
\hline & $\bar{n}$ & $\mathrm{M}(\mathrm{SD})$ & $B(95 \% \mathrm{Cl})$ & $\beta$ & $\overline{P \text { value }}$ & $B(95 \% \mathrm{Cl})$ & $\beta$ & $P$ value & $s r^{2}$ \\
\hline \multicolumn{10}{|c|}{$\begin{array}{l}\text { Grief intensity around time of death (TRIG } \\
\text { I) }\end{array}$} \\
\hline \multicolumn{10}{|l|}{ Place of death } \\
\hline Hospital & 158 & $20.78(8.25)$ & Ref. & & & Ref. & & & \\
\hline Home & 162 & $20.52(7.91)$ & $-0.25(-2.03$ to 1.52$)$ & -0.02 & 0.779 & $-2.44(-4.50$ to -0.39$)$ & -0.15 & 0.020 & 0.02 \\
\hline \multicolumn{10}{|c|}{ Relative's relationship to the patient } \\
\hline Spouse/partner & 130 & $21.85(8.16)$ & Ref. & & & Ref. & & & \\
\hline Son/daughter & 134 & $20.25(7.58)$ & -1.61 ( -3.55 to 0.33$)$ & -0.10 & 0.104 & -1.89 (-3.86 to 0.08$)$ & -0.12 & 0.060 & 0.01 \\
\hline Brother/sister & 15 & $17.87(6.32)$ & $-3.99(-8.29$ to 0.31$)$ & -0.11 & 0.069 & $-4.83(-9.09$ to -0.56$)$ & -0.13 & 0.027 & 0.02 \\
\hline Other & 40 & $19.45(9.40)$ & $-2.40(-5.25$ to 0.45$)$ & -0.10 & 0.098 & $-3.16(-6.14$ to -0.19$)$ & -0.13 & 0.037 & 0.01 \\
\hline \multicolumn{10}{|c|}{ Relative's presence at time of death } \\
\hline No & 94 & $19.04(8.51)$ & Ref. & & & Ref. & & & \\
\hline Yes & 225 & $21.24(7.72)$ & 2.19 (0.27 to 4.12$)$ & 0.13 & 0.026 & 2.41 (0.28 to 4.54$)$ & 0.14 & 0.027 & 0.02 \\
\hline \multicolumn{10}{|c|}{$\begin{array}{l}\text { Patient's preference for place of death } \\
\text { discussed with family }\end{array}$} \\
\hline No & 121 & $19.00(8.01)$ & Ref. & & & Ref. & & & \\
\hline Yes & 188 & $21.57(8.06)$ & 2.57 (0.73 to 4.42$)$ & 0.16 & 0.006 & 3.01 (1.11 to 5.03$)$ & 0.19 & 0.002 & 0.03 \\
\hline
\end{tabular}

Grief intensity at time of questionnaire completion (TRIG II)

Place of death

Hospital

Home

Relative's relationship to the patient

Spouse/partner

Son/daughter

Brother/sister

Other

Relative's presence at time of death

No

Yes

Relative's work arrangements in last three months of patient's life

0 to 3 days off work

4 to 14 days off work

$15+$ days off work

Not working

Patient's preference for place of death discussed with family

No

Yes

$123 \quad 41.83$ (13.86) Ref.

Ref.

18245.34 (11.96) 2.80 (0.52 to 5.09)

$0.11 \quad 0.016 \quad 2.88$ (0.07 to 5.82)

$0.11 \quad 0.056$

0.01

The TRIG was used to measure grief intensity for the respondent; the first scale asks respondents about their experience at the time of death (TRIG I 8-40 scale, 8 items, measured retrospectively) and the second scale asks about their experience at the time of questionnaire completion (TRIG II 13-65 scale, 13 items; higher scores meaning greater grief intensity; [30]). TRIG I model included 307 bereaved relatives ( $87.2 \%)$, with more missing amongst hospital deaths than amongst home deaths (16.4 \% vs. $9.1 \%, P=0.042$ ). Model statistics: $R$ for regression significantly different than zero, $F(9,297)=4.492, P<0.001 ; R^{2}=0.120$, adjusted $R^{2}=0.093$. TRIG II model included 281 bereaved relatives (79.8 \%), with no significant differences in the proportion missing amongst hospital deaths and home deaths ( $22.6 \%$ vs. $17.7 \%$, $P=0.254)$. Model statistics: $R$ for regression significantly different than zero, $F(12,268)=8.181, P<0.001 ; R^{2}=0.268$, adjusted $R^{2}=0.235$

$\mathrm{Cl}$, Confidence interval; B, Unstandardised regression coefficient; $\beta$, Standardised regression coefficient; M, mean; sr ${ }^{2}$, Semipartial correlation; SD, Standard deviation; TRIG, Texas Revised Inventory of Grief 


\section{Discussion}

To date, QUALYCARE is the most comprehensive population-based study of factors and outcomes associated with dying at home compared to hospital; it includes over 350 people who died from cancer and their relatives in the largest metropolitan area in the UK. The study fills in a critical gap in providing new evidence suggesting that dying at home is better than hospital for peace and grief, with no difference in the pain level experienced in the last week of life.

\section{Limitations}

There are limitations related to the study design, measurement, and analysis. The study is retrospective, and hence we show associations which do not necessarily indicate causality. It was conducted in London, therefore the transferability of findings to other regions where home care services (including palliative care) are less available, for example, is uncertain. The response rate was low (40\%), although it falls within the range of similar population-based postal surveys with bereaved relatives in the UK [35-37] and also compares to service-based surveys in the UK and Canada [38, 39]. Through sensitivity analysis, we identified no impact of non-response on the association of five variables with home death, although we were only able to examine a limited number of variables (those available for participants and non-participants).

The measurement of factors and outcomes was systematic and standardised but some variables (subjective factors, pain, peace) are vulnerable to recall and observer bias from respondents. Some studies suggest that relatives either overestimate or polarize their ratings of patient's pain 4-7 months after death compared to prospective reports [40, 41]. Our data do not show a polarization, but we cannot confirm whether the levels of pain, for example, were overestimated (this would require prospective data on the same patients). Even so, the pain prevalence found $(61.9 \%$ among patients who died at home, $70.1 \%$ among patients who died in hospital) was comparable to the pooled estimate of $64 \%$ (95\% CI, 58-69 \%) reported in a meta-analysis of advanced cancer patients, which excluded proxy data [42]. In contrast, it was lower than the weighted mean pain prevalence recently reported by Higginson et al. (76.1 \% and $73.9 \%$ including and excluding proxy data, respectively) [43]. These comparisons suggest that if there was overestimation, the magnitude of an effect on findings is likely to be small. The use of a postal method (which offers protection against social desirability) and the high salience of the events in question (circumstances surrounding the patient's death) might have increased recall accuracy in both cases and controls.

\section{Factors associated with dying at home}

We found several modifiable factors associated with place of death that are amenable to intervention and are rarely measured. Namely, we identified four conditions that are almost essential for patients to die at home rather than in hospital: patient's preference, relative's preference, receipt of home palliative care, and of district nursing/community nursing. The study also shows that, if patients get intensive nursing care specific to the end of life (provided by Marie Curie nurses), they very rarely die in hospital. However, $96 \%$ of those who died in hospital did not get such help. The study observes doseresponse relationships for two factors from a previous model [11]: hospital days and GP home visits. It challenges current thinking about the influence of patient's functional status, social conditions, and living arrangements, showing no association once other factors are considered. Importantly, we identified three factors previously overlooked - length of relative's awareness of incurability, discussion of patient's preference with family, and relative's work arrangements in the 3 months before death. Our final model explained well why some patients died at home whilst others died in hospital. Subject to testing, this may be effective for clinical decision-making.

\section{Preferences for place of death}

Given the importance of meeting people's preferences for place of death and preferences being one of the most influential factors on actual place of death, it is meaningful that home was reported as the preferred location of death for more than two thirds of patients in both groups. However, it should be noted that not all wish to die at home and that there are situations in which dying at home may not be feasible. Moreover, a home death was preferred by $92 \%$ of relatives of patients who died at home, but only by $32 \%$ of relatives of patients who died in hospital. Adding to findings from a systematic review of preferences for dying at home [1], we found a lower home preference from relatives compared to patients; this stresses the crucial role of families in caring for patients at home and in decision-making processes $[1,44]$. Most relatives said that their own preferences were stable in the last 3 months before death, with less than a fifth in both groups (cases and controls) changing their mind during this period. Early conversations about preferences involving patients and families seem, therefore, appropriate, provided they are well-conducted and preferences are monitored over time.

\section{Differences in outcomes between dying at home and in hospital}

Our findings suggest that, in addition to increasing choice, a home death is associated with similar experiences (in terms 
of pain) and sometimes better experiences and outcomes (in terms of peace and grief) for people dying of cancer and for their relatives. The study helps elucidate previous contradictory evidence on pain and grief, and provides some of the first evidence on sense of peace in relation to place of death.

\section{Pain}

The absence of a statistically significant difference in the levels of pain experienced by patients who died at home and by those who died in hospital concurs with some studies $[22,45]$ and disagree with others $[16,21]$. Our findings differ from a seminal study conducted by Parkes in London (1967-1971) [16], where among a sample of 165 patients, he found significantly greater pain at home than in hospital. However, Parkes included in the home group people who were at home for most of the time but were admitted to hospital in their last week of life. As it is possible that admission could be due to problems controlling pain, the inclusion of this sub-group in home deaths (18/65 of the home group) may have shaped the results.

It is indeed plausible that some patients who died in hospital were admitted because of more severe problems controlling pain at home, while those who stayed at home might have experienced fewer complications in the last week of life. It is also plausible that relatives were more aware of pain when people were at home, hence our findings on pain must be regarded with care. However, it is of relevance that, in QUALYCARE, the median level of pain was lower in the home group than in the hospital group, though the difference did not reach statistical significance. Interestingly, one recent study that shares the design, measurement, and timeframe with QUALYCARE (the EPACS study in Germany) found that patients who died at home were less likely to have experienced pain (57.8 \% vs. $67.9 \%)$ than patients who died in hospital [21].

\section{Peace}

Few studies have examined whether patients' sense of peace differs by place of death. Our findings support those from a small observational study in Philadelphia [46], where more bereaved relatives of patients who died at home thought these had been at peace than relatives of patients who died elsewhere $(16 / 18$ and $5 / 10$, respectively, $P=0.003$ ). In contrast, in the South West of the Netherlands, van der Heide et al. [45] found no differences in physicians' perspectives on whether the patient died peacefully between those who died at home and elsewhere $(29 / 42$ and $28 / 41$, respectively, $P=0.94)$. However, this finding is limited to the degree the physicians were involved and present in the last days of life (which was unknown).
The one point difference in median peace scores between the home and hospital groups (4, i.e. most of the time, compared to 3, i.e. some of the time, measured through the POS peace item with a $0-5$ range) is of clinical significance. However, both medians were higher (i.e. better) than the threshold recommended by Selman et al. [47] as indicative of distress in the POS peace item, i.e. scores of $0-1$. Applying this threshold, the differences are still evident: $11.8 \%$ of patients who died at home and $24.8 \%$ of those who died in hospital were on or below the recommended threshold, indicating distress.

It is possible that this difference reflects the importance of some of the dimensions that Selman et al. [47] identified in the concept of peace with patients. These include being aware and accepting death, but also relational aspects such as the ability to be at home with family. However, the association of home death with increased peace persisted when adjusted for relative's awareness of incurability, family discussion of preferences for place of death, and respondent's relationship to the patient. The finding of differences in peace but not in pain suggests the former may encompass but transcends the latter. Other aspects may play a role, for example, those related to the environment in hospitals (noisy and busy settings) and the patient's consciousness level (e.g. being asleep may be regarded by the relatives as being peaceful).

\section{Grief}

Our findings showing less intense grief for relatives in the home group refute previous UK population-based data from the 1990's [18]. RSCD investigators found that bereaved relatives of patients who died at home had higher levels of psychological distress around 10 months after the patient died as measured by the GHQ-28 (mean score 24.7 compared to 22.2, $P<0.01$ ) and were more likely to say they missed the deceased a great deal, and less likely to say that they had come to terms with the death, that they looked forward to things as usual, or that things were going reasonably well for them by then. The results on the two latter aspects were similar in the sub-group of spouses, whilst differences in the former two lost significance in this sub-group. No adjustments were made to the results, though, and this is important because relatives of patients who die at home are more likely to be spouses, but also more likely be present at the time of death, factors we found were associated with greater grief intensity. Adjusting for these confounders is, therefore, important.

In addition, the RSCD compared psychological distress and three items measuring cognitive and emotional aspects of grief. However, grief encompasses other important facets (e.g. behavioural, relational) [48]. In 
QUALYCARE, we measured the whole construct of grief, using a validated measure with high Cronbach's alphas, demonstrating good internal consistency for the purpose of comparing groups [32]. However, it is more plausible that adjustments rather than measurement issues explain the differences between our results and the RSCD. It is also likely that home support increased over time (from 1990 to 2010), which may impact on grief adjustment.

Our findings concur with the Coping with Cancer study conducted more recently in the US [19], which showed that relatives of patients who died in hospital were at heightened risk of prolonged grief disorder (assessed using a validated scale) compared to relatives of patients who died at home with hospice care (AOR, 8.83; $95 \% \mathrm{CI}, 1.51-51.77)$. An important finding from the Coping with Cancer study was that none of the psychological variables measured at baseline (median 4.5 months before the patient died) were associated with place of death, which suggests pre-bereavement psychological morbidity may not confound the effect of place of death on post-bereavement complications. QUALYCARE results on grief also align with the Cambridge Hospital at Home randomised controlled trial in the UK [49].

\section{Implications for clinical practice}

It is clear from the findings that most people dying of cancer prefer to die at home and that this wish is often supported by family, yet seldom met. Those that do die at home (in regions of London) appear to spend their last days in greater peace, nearly always with family around them, and with pain controlled to a similar level to those who die in hospital. Based on the data, nearly two fifths of the people who die of cancer at home in the regions in the study can expect a pain-free death. Around another fifth are affected only slightly - this makes over half of all home deaths in cancer. Such encouraging reality reflects multiple factors, which include the work of clinicians on the ground, particularly of those working in the community, to ensure that patients and families are adequately supported at home. Yet, the findings highlight the need to do more. There are some people for whom death at home is not peaceful and pain-free, and there are relatives that are left in intense grieving. Input from home palliative care services, district/community nurses, and GPs is essential, but not enough to guarantee to a patient with advanced cancer who wants to die at home that they will achieve their wish. Other factors in our model (Figs. 2 and 3) require attention from all clinicians involved in cancer care in terms of risk assessment and care management.

\section{Conclusions}

QUALYCARE presents novel knowledge suggesting that dying at home is better than hospital for peace and grief, and it also shows what needs to be in place for advanced cancer patients to die at home if they wish. Examining the variations associated with home death in cancer in a comprehensive way revealed that dying at home is a complex yet tangible goal, one that can be achieved in comfortable conditions. The findings indicate that making this a reality for more patients with incurable cancer requires a wide response: from oncologists to check the identified risk factors and discuss preferences with patients and families, from GPs to be proactive and make home visits, and from policymakers to implement comprehensive home care packages and develop measures to sustain family involvement in care. Failure to do this may contribute to crises and subsequent admissions, leading to an undesired death in hospital, less peaceful than can be achieved at home and more difficult for relatives to live with.

\section{Additional files}

Additional file 1: Ecological analysis of cancer home death rates and deprivation levels in London. (DOCX $97 \mathrm{~kb}$ )

Additional file 2: Discrepancies in place of death information: death registration versus questionnaire data. (DOCX $11 \mathrm{~kb}$ )

Additional file 3: Factors potentially associated with home death: source and coding. (DOCX $30 \mathrm{~kb}$ )

Additional file 4: Outcome measurement: pain, peace, and grief. (DOCX $15 \mathrm{~kb}$ )

Additional file 5: Model of death at home in cancer tested in the QUALYCARE study. (DOCX $14 \mathrm{~kb}$ )

Additional file 6: Recruitment flow diagram. (DOCX 51 kb)

Additional file 7: Bivariate analysis of factors associated with home death. (DOCX $24 \mathrm{~kb}$ )

Additional file 8: Sub-analysis of five-factor model with patients who preferred to die at home. (DOCX $16 \mathrm{~kb}$ )

Additional file 9: Sensitivity analysis of non-participation on factors associated with home death. (DOCX $21 \mathrm{~kb})$

\section{Abbreviations}

AOR: Adjusted odds ratio; GP: General practitioner; IQR: Interquartile range; NIHR: National Institute of Health Research; ONS: Office for National Statistics; POS: Palliative care Outcome Scale; RSCD: Regional Study of Care for the Dying; TRIG: Texas Revised Inventory of Grief.

Competing interests

The funder (Cicely Saunders International) had no role in the study design, in the collection, analysis and interpretation of data, the writing of this manuscript or in the decision to submit it. The authors have received funding in the past 5 years from the Department of Health (partner in the study) for conducting end-of-life care research and, although unlikely, it is possible this organisation may gain or lose financially from the publication of this manuscript. The authors declare that they have no other competing interests.

\section{Authors' contributions}

$B G, J K$, and $I J H$ conceived the study and participated in its design. BG and NC conducted data collection and assembly. All authors participated in data analysis. All authors were involved in the interpretation of the analyses and writing of the paper. All authors read and approved the final manuscript. 


\section{Acknowledgements}

We are most grateful to all the study participants. We thank Cicely Saunders International for the financial support needed to undertake this study including Barbara Gomes' PhD Research Training Fellowship. The study involved many collaborators, to whom we are indebted: Professor Paul McCrone and Dr Sue Hall at King's College London, the Department of Palliative Care at the Royal Marsden Hospital (Dr Julia Riley, Meena Valambhia, among others); Dr Elizabeth Davies and Dr Peter Madden at the Thames Cancer Registry; Professor Mike Richards and Tessa Ing on behalf of the Department of Health; the ONS Health Analysis team (Myer Glickman, Peter Davies, Stephen Rowlands, Justine Pooley); the Islington, Westminster, Bromley, and Sutton \& Merton Primary Care Trusts (Nada Lemic, Sarah Price, Clare Henderson, Jacqui Lindo, Ursula Daee, end-of-life care groups, communication teams); the South East London Cancer Research Network (Kerry Hylands for data entry and governance advice). We thank the members of the project steering group, patient/family representatives (Nell Dunn, Kirstie Newson), the international scientific expert panel from Cicely Saunders International, Brenda Ferns, and external advisors (Dr Anita Patel, Professor Colin Murray Parkes, Dr Joana Cadima, Dr Massimo Costantini). We also thank the local services that helped us understand better the findings, including staff at St. Christopher's Hospice, the ELiPSe team, and colleagues at King's College London (Claudia Bausewein, Despina Anagnostou, Emma Murphy, Fliss Murtagh, Gao Wei, Lucy Selman, Marjolein Gysels, Sian Best, Thomas Osborne and Vera Sarmento, among others). Thanks to the Calouste Gulbenkian Foundation for patience and encouragement. We are also grateful to Professor Gunn Grande and Professor Christine Ingleton for their review and insightful comments.

\section{Author details}

'King's College London, Cicely Saunders Institute, Department of Palliative Care, Policy and Rehabilitation, Bessemer Road, SE5 9PJ London, UK. ${ }^{2}$ University of Edinburgh, Medical School, Centre for Population Health Sciences, Teviot Place EH8 9AG, Edinburgh, UK.

\section{Received: 16 April 2015 Accepted: 28 August 2015}

Published online: 09 October 2015

\section{References}

1. Gomes B, Calanzani N, Gysels M, Hall S, Higginson IJ. Heterogeneity and changes in preferences for dying at home: a systematic review. BMC Palliat Care. 2013;12:7.

2. Gomes B, Higginson IJ, Calanzani N, Cohen J, Deliens L, Daveson BA, et al. Preferences for place of death if faced with advanced cancer: a population survey in England, Flanders, Germany, Italy, The Netherlands, Portugal and Spain. Ann Oncol. 2012;23:2006-15.

3. Gomes B, Calanzani N, Higginson IJ. Reversal of the British trends in place of death: time series analysis 2004-2010. Palliat Med. 2012;26:102-7.

4. Flory J, Yinong YX, Gurol I, Levinsky N, Ash A, Emanuel E. Place of death: US trends since 1980. Health Aff. 2004;23:194-200.

5. Wilson DM, Truman CD, Thomas R, Fainsinger R, Kovacs-Burns K, Froggatt K, et al. The rapidly changing location of death in Canada, 1994-2004. Soc Sci Med. 2009;68:1752-8.

6. Yang L, Sakamoto N, Marui E. A study of home deaths in Japan from 1951 to 2002. BMC Palliat Care. 2006:9:2.

7. Mystakidou K, Parpa E, Tsilika E, Galanos A, Patiraki E, Tsiatas S, et al. Where do cancer patients die in Greece? A population-based study on the place of death in 1993 and 2003. J Pain Symptom Manage. 2009;38:309-14.

8. Simon ST, Gomes B, Koeskeroglu P, Higginson IJ, Bausewein C. Population, mortality and place of death in Germany (1950-2050) - implications for end-of-life care in the future. Public Health. 2012;126:937-46.

9. Sarmento VP, Higginson IJ, Ferreira PL, Gomes B. Past trends and projections of hospital deaths to inform the integration of palliative care in one of the most ageing countries in the world. Palliat Med. 2015. Ahead of print. doi:10.1177/0269216315594974.

10. Broad JB, Gott M, Kim H, Boyd M, Chen H, Connolly MJ. Where do people die? An international comparison of the percentage of deaths occurring in hospital and residential aged care settings in 45 populations, using published and available statistics. Int J Public Health. 2013;58:257-67.

11. Gomes B, Higginson IJ. Factors influencing death at home in terminally ill patients with cancer: systematic review. BMJ. 2006;332:515-21.
12. Cohen J, Houttekier D, Onwuteaka-Philipsen B, Miccinesi G, Addington-Hall J, Kaasa S, et al. Which patients with cancer die at home? A study of six European countries using death certificate data. J Clin Oncol. 2010;28:2267-73.

13. Oncol L. Dignity in death: the triumph of politics over evidence. Lancet Oncol. 2013;14:1243-56.

14. Mariotto AB, Yabroff KR, Shao $Y$, Feuer EJ, Brown M. Projections of the cost of cancer care in the United States: 2010-2020. J Natl Cancer Inst. 2011;103:117-28.

15. Higginson IJ, Sarmento VP, Calanzani N, Benalia H, Gomes B. Dying at home - is it better: a narrative appraisal of the state of the science. Palliat Med. 2013;27:918-24.

16. Parkes CM. Home or hospital? Terminal care as seen by surviving spouses. J R Coll Gen Pract. 1978;28:19-30.

17. Escobar PLC, Weber M, Claus M, Fischbeck S, Unrath M, Martini T, et al. Factors influencing place of death in Germany. J Pain Symptom Manage. 2011;41:893-903.

18. Addington-Hall J, Karlsen S. Do home deaths increase distress in bereavement? Palliat Med. 2000;14:161-2.

19. Wright AA, Keating NL, Balboni TA, Matulonis UA, Block SD, Prigerson HG. Place of death: correlations with quality of life of patients with cancer and predictors of bereaved caregivers' mental health. J Clin Oncol. 2010;28:4457-64.

20. Tang ST. Influencing factors of place of death among home care patients with cancer in Taiwan. Cancer Nurs. 2002;25:158-66.

21. Escobar PLC, Claus M, Zepf KI, Fischbeck S, Weber M. Symptom prevalence in the last days of life in Germany: the role of place of death. Am J Hosp Palliat Care. 2012;29:431-7.

22. Jordhoy MS, Saltvedt I, Fayers P, Loge JH, Ahlner-Elmqvist M, Kaasa S Which cancer patients die in nursing homes? Quality of life, medical and sociodemographic characteristics. Palliat Med. 2003;17:433-44.

23. Ringdal Gl, Jordhoy MS, Ringdal K, Kaasa S. Factors affecting grief reactions in close family members to individuals who have died of cancer. J Pain Symptom Manage. 2001;22:1016-26.

24. Gomes B, McCrone P, Hall S, Koffman J, Higginson IJ. Variations in the quality and costs of end-of-life care, preferences and palliative outcomes for cancer patients by place of death: the QUALYCARE study. BMC Cancer. 2010:2:400.

25. Department of Health. End of Life Care Strategy - Promoting high quality care for all adults at the end of life. London: Department of Health; 2008.

26. Altman DG. Practical statistics for medical research. London: Chapman and Hall; 1991.

27. Gomes B, McCrone P, Hall S, Riley J, Koffman J, Higginson IJ. Cognitive interviewing of bereaved relatives to improve the measurement of health outcomes and care utilisation at the end of life in a mortality followback survey. Support Care Cancer. 2013;21:2835-44.

28. Hearn J, Higginson IJ. Development and validation of a core outcome measure for palliative care: the palliative care outcome scale. Palliative Care Core Audit Project Advisory Group. Qual Health Care. 1999;8:219-27.

29. Harding R, Selman L, Agupio G, Dinat N, Downing J, Gwyther L, et al. Validation of a core outcome measure for palliative care in Africa: the APCA African Palliative Outcome Scale. Health Qual Life Outcomes. 2010;25:10.

30. Faschingbauer TR. Texas Revised Inventory of Grief manual. Houston, TX: Honeycomb Publishing Company; 1981

31. Bland JM, Altman DG. Cronbach's alpha. BMJ. 1997;314:572.

32. Koffman J, Higginson IJ, Hall S, Riley J, McCrone P, Gomes B. Bereaved relatives' views about participating in cancer research. Palliat Med. 2012;26:379-83.

33. Hosmer DW, Lemeshow S. Applied logistic regression. 2nd ed. New York, Chichester: Wiley; 2000

34. Department of Communities and Local Government. The English indices of deprivation 2010. London: Department of Communities and Local Government; 2011.

35. Jacoby A, Lecouturier J, Bradshaw C, Lovel T, Eccles M. Feasibility of using postal questionnaires to examine carer satisfaction with palliative care: a methodological assessment. South Tyneside MAAG Palliative Care Study Group. Palliat Med. 1999;13:285-98.

36. Ingleton C, Morgan J, Hughes P, Noble B, Evans A, Clark D. Carer satisfaction with end-of-life care in Powys, Wales: a cross-sectional survey. Health Soc Care Community. 2004;12:43-52.

37. Hunt KJ, Shlomo N, Addington-Hall J. End-of-life care and achieving preferences for place of death in England: results of a population-based survey using the VOICES-SF questionnaire. Palliat Med. 2014;28:412-21. 
38. Grande GE, Ewing G. National Forum for Hospice at Home. Informal carer bereavement outcome: relation to quality of end of life support and achievement of preferred place of death. Palliat Med. 2009;23:248-56.

39. Brazil K, Bainbridge D, Ploeg J, Krueger P, Taniguchi A, Marshall D. Family caregiver views on patient-centred care at the end of life. Scand J Caring Sci. 2012;26:513-8.

40. Higginson I, Priest P, McCarthy M. Are bereaved family members a valid proxy for a patient's assessment of dying? Social Sci Med. 1994;38:553-7.

41. Hinton J. How reliable are relatives' retrospective reports of terminal illness? Patients and relatives' accounts compared. Social Sci Med. 1996:43:1229-36.

42. van den Beuken-van Everdingen MH J, de Rijke JM, Kessels AG, Schouten HC, van Kleef M, Patijn J. Prevalence of pain in patients with cancer: a systematic review of the past 40 years. Annals Oncol. 2007;18:1437-49.

43. Higginson IJ, Murtagh FEM, Osborne TR. Epidemiology of pain in cancer. In: Cancer pain. London: Springer; 2013. p. 5-24.

44. Higginson IJ, Hall S, Koffman J, Riley J, Gomes B. Time to get it right: are preferences for place of death more stable than we think? Palliat Med. 2010;24:352-3.

45. van der Heide A, de Vogel-Voogt E, Visser AP, van der Rijt CCD, van der Maas PJ. Dying at home or in an institution: perspectives of Dutch physicians and bereaved relatives. Support Care Cancer. 2007;15:1413-21.

46. Phipps EJ, Braitman LE. Family caregiver satisfaction with care at end of life: report from the cultural variations study (CVAS). Am J Hosp Palliat Care. 2004;21:340-2.

47. Selman L, Harding R, Gysels M, Speck P, Higginson IJ. The measurement of spirituality in palliative care and the content of tools validated crossculturally: a systematic review. J Pain Symptom Manage. 2011;41:728-53.

48. Prigerson HG, Horowitz MJ, Jacobs SC, Parkes CM, Aslan M, Goodkin K, et al. Prolonged grief disorder: psychometric validation of criteria proposed for DSM-V and ICD-11. PLoS Med. 2009;6:e1000121.

49. Grande GE, Farquhar MC, Barclay SIG, Todd CJ. Caregiver bereavement outcome: relationship with hospice at home, satisfaction with care, and home death. J Palliat Care. 2004:20:69-77.

\section{Submit your next manuscript to BioMed Central and take full advantage of:}

- Convenient online submission

- Thorough peer review

- No space constraints or color figure charges

- Immediate publication on acceptance

- Inclusion in PubMed, CAS, Scopus and Google Scholar

- Research which is freely available for redistribution 